\section{Moral Sense and Ethic.}

IN the criticism of Mr. Sutherland's book by "F. G." (NATURE, July I4, p. 24I), no notice is taken of the distinction between moral sentiments and ethical perceptions. Perhaps this distinction is most evident in cases where a man, or woman, perceives an action to be a bad one, and at the same time prefers to do it, and does it.

At p. 249 Principal Lloyd Morgan quotes Mr. Thorndike as saying, of writings about animals, that "they have all been about animal intelligence, never about animal stupidity." The chapter on "the animal facuities" in my work "On Truth," contains a distinct section (p. 355) devoted to "animal stupidity," which is also referred to (p. 124) in my "Origin of Human Reason."

77 Inverness Terrace, W., July I 5 .

\section{Curious Phenomenon.}

ON July 8, at about 8.50 (Mean European time), I noticed what I took at first to be the end of a rainbow. The sky was nearly cloudless towards the north; $30^{\circ}$ south of the zenith ing still when considered in connection with Dufour's observation touching the freedom of the Algerian Solpugas from persecution by the solitary wasps. The importance of the fact he records, moreover, would be considerably increased if the reason why the honey-bees of California permit the intrusion of their hives by these Arachnoids was explained. Such an explanation might perhaps furnish a solution to the hitherto unanswered problem why the wasps let the Solpugas alone.

R. I. Pocock.

THE BUILDINGS AT SOUTH KENSINGTON.

$\mathrm{SO}$ far there does not appear to be anything finally settled with regard to the allocation of space to the Science and Art Buildings at South Kensington. While on the one hand Mr. Akers Douglas has declined to give any information to the Chairman of the Select Committee which made the recommendations which have since been strenuously supported by the representatives of Science and Art; on the other, the Birmingham Daily

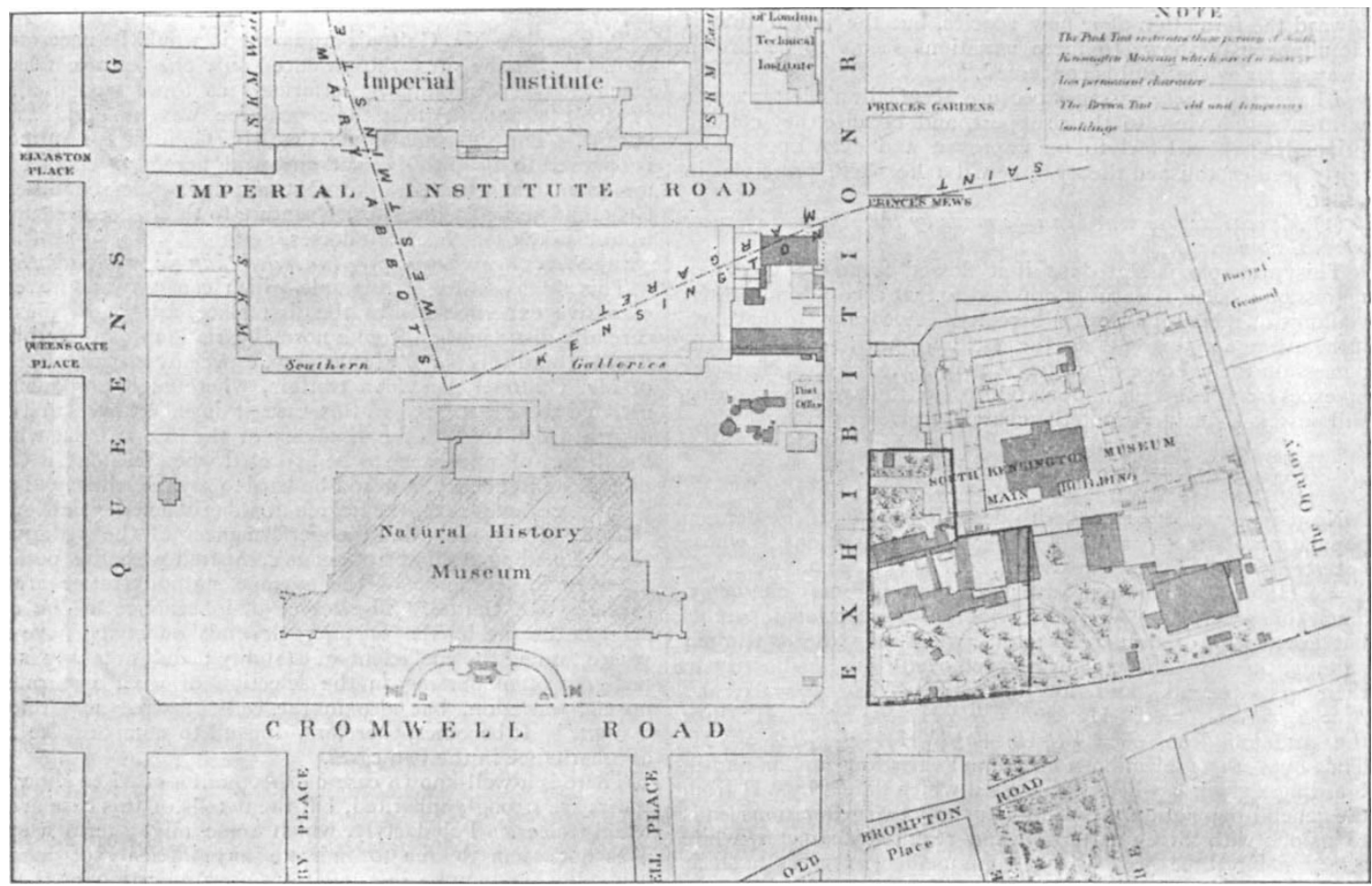

FIG. I - The neighbourhood of the South Kensington and Natural History Museums, showing the space (bounded by a black line) available for Science buildings on the east side of Exhibition Road.

began a mass of grey clouds, tinged here and there with red till about $15^{\circ}$ from the horizon. Below the lowest of the red clouds was an object, about as broad as a rainbow, a degree or two E. of S., and about $12^{\circ}$ high. It was red, but in the first few moments I thought I detected a tinge of green on the E. side. It remained in its original brightness about five minutes, then faded very rapidly, and then remained almost stationary again, finally disappearing about eight minutes after I first saw it. The sun had, so far as I could judge, set about five or ten minutes before I noticed the appearance. I am quite sure of the time, as we have a mid-day gun. 9 Gerhard Street, Kiel.

N. W. Thomas.

The Nature and Habits of Pliny's Solpuga.

Although of great interest in itself, the note by Prof. Cook, in NATURE for July 14, p. 247, becomes more interestNO. I 500 , VOL. 58$]$
Post announces that the matter has been settled on the lines of the recommendations in question.

In order that the exact nature of the question at issue between the representatives of Science and Art on the one hand, and certain Government officials on the other, may be clearly grasped, it is only necessary to follow up the statistics given by Sir Philip Magnus in his article on Technical High Schools (NATURE, May I9). In this article a comparison was made of the area occupied by the Royal College of Science with that of several German technical schools, one of the results which clearly comes out being that some of the latter are ten times bigger than the College.

It has long been known to the Government that the College is too small. Physics, Astronomical Physics, Geology, Mining, Metallurgy and Mechanics have had 